his readers many ideas to think about, not all of them popular, but all deserving of attention.

Greer is not altogether impressed by empiricism. His thought, which owes much to the late A. N. Whitehead, shows him to be uneasy about the philosophical poverty of modern science, in spite of the rich harvest that has been garnered as a result of sheer empiricism. In social science, however, the harvest is better when conceptual thought has preceded data collection than when research has merely relied on empirical techniques. It is discussion of such conceptual thought which engages his attention. Much of what he says is not new, but it does bear repetition. His book is divided into four parts, treating respectively the "Scientific Position", "Abstraction and Innovation", "A Working Definition" and "Social Science and Values".

A book such as this is mainly written for the professional social scientist teaching methods of enquiry; this raises the question of the pedagogical function of the subject. We live in an age when people are more selfconscious about their society than they were, an age which requires more and more deliberate thought about social processes. A social science which teaches merely empirical research techniques, valuable and useful though these may be, will fail to meet the needs of the times. It is precisely the training of young minds to think in a disciplined but imaginative way about social structures and processes that is important. We must apply seientific method to social studies without being besotted by a scientistic philosophy and pragmatism. As the author says: "No one lives by science but nobody lives without it". The task of social science is an immense one. Properly developed, it can do much, but there are some things it cannot do. It cannot judge on policy matters, although it may do much to inform such judgments. It cannot provide a Weltanschauung, but it can enlarge our ideas, deepen our understanding and enable us to avoid uttering silly, muddle-headed and dangerous remarks about human behaviour.

The Logic of Social Inquiry contains some nice epigrams, a few unnecessary neologisms, for example, "fleshed", "diagrammed", "patterned" (verbs) and "dramatistic", and it is written in that slightly mannered style which some American scholars affect, but the contents are a useful corrective to the nonsense written about two cultures. Social science is a major contribution to the culture of modern man, although Lord Snow and some others seem to have overlooked its significance.

G. Dundan Mitchell

\section{BACKWARDNESS IN READING}

\section{Patterns of Impairment in Specific Reading Disability}

A Neuropsychological Investigation. By Donald G. Dochring. Pp. xii +193 . (Indiana University Press: Bloomington and London, February 1969.) 5ls paper.

SEVERE backwardness in reading in children of otherwise normal intelligence was first described by Hinshelwood in 1895. In accordance with the neurology of the time, he regarded it as analogous to alexia in the adult and attributed it to defective development of the angular gyrus and related areas of the left cerebral hemisphere. Although the dependence of what came to be called "congenital word-blindness" on specific defect in cerebral structure or function has never been unequivocably established, it is at least clear that there are forms of reading backwardness that arise neither from lack of intelligence nor from want of opportunity to learn to read. It is to these conditions that the term "specific reading disability" (or' developmental dyslexia) is commonly applied.

In this monograph, Doehring reports a major investigation of dyslexia which he undertook at the Indiana University Medical Center, under the aegis of Professor A. L. Drew, director of the Paediatric Neurology Clinic, and R. M. Reitan, director of the Neuropsychology Laboratory. He selected a "specific reading disability group" of thirty-nine boys in the 10-14 year age-range whose reading attainment was two or more years below the expected school grade and with IQ on the WechslerBellevue Performance Scale of not less than 90. These children were said to be entirely normal from the point of view of general physical health, vision and hearing (as ordinarily ascertained), psychiatric status and educational opportunity. Their performance on a wide variety of psychological tests was compared with that of a carefully matched control group of thirty-nine boys from the same population whose reading achievement was within the normal range and with no history of reading disability. All the retarded and more than half the normal readers were also given a formal neurological examination and case history information was obtained by interview.

Test-by-test statistical comparisons seem to show clearly that the disability in the group of backward readers was not entirely restricted to reading and spelling. For example, performance on tests of defining words (vocabulary) or rhyming was significantly below that of the group of normal readers, as was also performance on certain tests of visual perceptual speed. (It is doubtful, however, whether the latter have much practical implication.) While the pattern of test performance did not entirely conform to that observed in brain-injured adults, Doehring points out that it did resemble fairly closely that observed in adult cases of aphasia complicated by central involvement of higher visual processes. Some support for this view was forthcoming from the findings of neurological examination.

Although Doehring puts forward no new theory, he calls attention to a number of points that may prove of great value in future research. One is his suggestion that a defect in sequential processing may be associated with, or even underlie, dyslexia - a suggestion that has also been put forward by workers in this country. Unlike British workers, however, Doehring reports no excess of perinatal complications or sinistrality in his group of retarded readers but finds some evidence of a familial, presumably genetical, factor.

This monograph makes a most useful contribution to our knowledge of backwardness in reading and should be carefully studied by all with an interest in this important - though until recently grossly neglected-field of educational research. Although the methodology is severe and the description of tests so compressed as to convey almost no information to those without previous knowledge, the report is clearly written and its main findings are easily understood. It should do much to undermine the still widely held belief that backwardness in reading is a purely psychological affair that can be understood (and treated) without reference to brains or genes.

O. L. ZANGWILI

\section{BLOOD MARKERS}

\section{Genetic Markers in Human Blood}

By Eloise R. Giblett. Pp. xxvii +629 . (Blackwell (Scientific) : Oxford and Edinburgh, 1969.) $85 s$.

A LARGE part of our knowledge of human genetics is derived from work on blood, both on the plasma and on its formed elements. 'There have been books on some parts of this field, such as the blood groups, the immunoglobulins, and the haemoglobins; indeed, in the case of haemoglobins, for example, there have been monographs on special aspects, such as the thalassaemias and methremoglobinaemias. It is therefore a big undertaking to produce a representative account of the genetic markers in human blood within one volume of some 600 pages. Perhaps the fact that Professor Eloise R. Giblett has succeeded in doing so has something to do with her having made herself original contributions to several of these systems 